\title{
PARA ALÉM DO IR E VIR: O CONCEITO NORMATIVO BRASILEIRO DE TRABALHO ESCRAVO ANTE O DIREITO COMPARADO
}

\section{BEYOND COMING AND GOING: THE BRAZILIAN LEGAL DEFINITION OF SLAVE LABOR VIS-À-VIS THE COMPARATIVE LAW}

\author{
Silvio Beltramelli Neto \\ Faculdade de Direito da PUC-Campinas. Ministério Público do Trabalho (Campinas, SP, Brasil)
}

Felipe da Silva Pinto Adão

Ministério Público do Trabalho (Campinas, SP, Brasil)

Recebimento: 26 jul. 2016

Aceitação: 2 dez. 2016

\begin{abstract}
Como citar este artigo / How to cite this article (informe a data atual de acesso / inform the current date of access):
BELTRAMELli NETO, Silvio; ADÃO, Felipe da Silva Pinto. Para além do ir e vir: o conceito normativo brasileiro de trabalho escravo ante o direito comparado. Revista da Faculdade de Direito UFPR, Curitiba, PR, Brasil, v. 62, n. 1, jan./abr. 2017, p. 113 - 136. ISSN 2236-7284. Disponível em: <http://revistas.ufpr.br/direito/article/view/47832>. Acesso em: 30 abr. 2017. DOI: http://dx.doi.org/10.5380/rfdufpr.v62i1.47832.
\end{abstract}

\section{RESUMO}

O artigo propõe-se a investigar se o conceito normativo brasileiro de trabalho escravo se afigura instrumento adequado às ações de prevenção e repressão à escravidão contemporânea, a partir de seu cotejo com determinadas normas e decisões internacionais, de repercussão global. Comparar-se-á a definição legal nacional de redução à condição análoga à de escravo com os referenciais normativos atinentes ao caso Prosecutor versus Kunarac et al., julgado pelo Tribunal Penal Internacional para a antiga Iugoslávia, em 2002; ao caso R. versus Tang, julgado pela Suprema Corte da Austrália, em 2008; ao Modern Slavery Act, lei aprovada pelo Parlamento inglês, em 2015; e, finalmente, ao Guia Interpretativo do artigo $4^{\circ}$ da Convenção Europeia de Direitos Humanos, editado pela Corte Europeia de Direitos Humanos, em 2014, notadamente no que se refere ao caso Siliadin versus França. Pretende-se evidenciar, com esta análise comparativa, o caráter vanguardista e a adequação do conceito normativo brasileiro ao enfrentamento das formas contemporâneas de escravidão.

\section{PALAVRAS-CHAVE}

Trabalho escravo contemporâneo. Conceito normativo. Liberdade de locomoção. Dignidade humana. Direito comparado.

\begin{abstract}
This article seeks to examine whether the Brazilian legal definition of slave labour stands as an adequate tool for the measures aimed towards prevention and repression of modern slavery by way of confronting it with some international statutes and legal decisions of global repercussion. A comparison will be made between the legal definition of slavery in Brazil and the legal references laid down on the case Prosecutor v. Kunarac et al., ruled by the International Criminal Tribunal for the former Yugoslavia, in 2002; on the case R. v. Tang, ruled by the High Court of Australia in 2008; on the Modern Slavery Act, a bill passed by the UK Parliament in 2015; and, finally, on the Guide on Article 4 of the European Convention on Human Rights, edited by the European Court of Human
\end{abstract}


Rights in 2014, concerning the specific parts in which the case of Siliadin v. France is referenced. The article seeks to highlight, through this comparative analysis, the Brazilian legal definition of slavery's pioneering character and its adequacy to fight the contemporary forms of slavery.

\section{KEYWORDS}

Contemporary slavery. Legal definition. Freedom of locomotion. Human dignity. Comparative law.

\section{INTRODUÇÃO}

O presente trabalho propõe-se a examinar a atualidade do conceito normativo brasileiro de trabalho escravo e sua aptidão como instrumento para o enfrentamento das formas contemporâneas de manifestação desse fenômeno, a partir de seu cotejo com referências legislativas e jurisprudenciais de direito comparado, representativas de um padrão conceitual global. Após breve panorama da incidência recente da escravidão no Brasil, a análise será desenvolvida a partir da comparação do tipo penal nacional alusivo à redução a condição análoga à de escravo com os padrões normativos atinentes ao caso Prosecutor versus Kunarac et al., julgado pelo Tribunal Penal Internacional para a antiga Iugoslávia, em 2001; ao caso R. versus Tang, julgado pela Suprema Corte da Austrália, em 2008; ao recente Modern Slavery Act, norma aprovada pelo Parlamento inglês, em 2015; e, finalmente, ao Guia Interpretativo do artigo $4^{\circ}$ da Convenção Europeia de Direitos Humanos, editado pela Corte Europeia de Direitos Humanos, em 2014, com menção ao Caso Siliadin versus França.

A eleição dos paradigmas justifica-se. Tanto o caso Prosecutor versus Kunarac et al. como o Guia Interpretativo da Corte Europeia de Direitos Humanos são icônicos por estabelecerem a posição de dois relevantes tribunais internacionais de direitos humanos sobre o tema. Por sua vez, o caso R. versus Tang, a despeito de sua apreciação por um tribunal nacional, tornou-se parâmetro para pesquisas sobre tráfico de pessoas, constando até mesmo da base de dados sobre casos emblemáticos da Organização das Nações Unidas (2009).

Advirta-se, de antemão, que a consideração das questões históricas, políticas e sociais inerentes ao tema e aos contextos brasileiro e dos cases trazidos a cotejo não está em causa nesta reflexão, tampouco o complexo conjunto de alterações e providências capazes de conduzir à eliminação da escravidão, sobretudo no País, em que pese referências a respeito tenham tangenciado a análise.

Por certo, a erradicação da escravidão contemporânea imprescinde de perquirição histórica aprofundada das desigualdades sociais que impulsionam o trabalho escravo. Todavia, este escrito, por sua brevidade, centra-se em uma análise comparativa direta de enunciados normativos e de expressões jurisprudenciais de sua aplicação. Tal opção explica-se, uma vez que as idiossincrasias e 
disputas políticas e sociais acerca de qualquer tema sensível aos direitos humanos costumam estar mais à vista quando suscitadas controvérsias acerca do modo como a lei trata o fato e, igualmente, como se dá correlata aplicação da norma ao caso concreto (ato interpretativo). Examinar, portanto, a mensagem mais imediata de um dispositivo legal, neste contexto, significa investigar o grau de reprovabilidade social da conduta e, consequentemente, o estágio de amadurecimento institucional acerca do fato social em si.

Nessa linha, o recorte eleito remete a uma disputa viva e atual, travada no Congresso Nacional brasileiro, acerca da manutenção ou alteração do conceito normativo pátrio de escravidão contemporânea, demonstrando que o entendimento da norma posta é aspecto nuclear - conquanto longe de ser exclusivo - da construção/aperfeiçoamento ou, ao contrário, da obstaculização de uma agenda institucional de combate ao trabalho escravo contemporâneo.

Com esta inspiração não exauriente, mas de contribuição ao debate pela análise de um aspecto que lhe é sensível, pretende-se, pois, investigar se o conceito normativo brasileiro de trabalho escravo, tal como se encontra posto, afigura-se instrumento adequado às ações de prevenção e repressão à escravidão contemporânea, a partir, notadamente, de sua comparação com o quanto delineado em expressivas manifestações legislativas e jurisprudenciais internacionais.

\section{PANORAMA DA ESCRAVIDÃO CONTEMPORÂNEA NO BRASIL}

O trabalho escravo ainda representa uma das grandes chagas da sociedade brasileira, permanecendo na sombra de todas as principais relações de consumo, às quais subjazem, não raras vezes, modos de produção que são levados a efeito mediante o aniquilamento da dignidade humana, resultante da coisificação do indivíduo em níveis mais profundos.

É certo que a escravidão nunca deixou de fazer parte da sociedade brasileira, embora com distintas feições, oriundas das diferentes formas de dominação que se moldaram e ainda se moldam a partir das alterações que afetam o próprio modo de produção e, por conseguinte, as formas de violência empregadas para além da ameaça física (servidão por dívidas, retenção de documentos e restrição de alimentação, moradia e transporte, entre outras).

O tema ganhou mais notoriedade nas décadas de sessenta, setenta e oitenta, por obra de denúncias levadas a público, ao Estado e a órgãos internacionais pela Igreja Católica e por representação de trabalhadores, mesmo momento em que a Organização Internacional do Trabalho (OIT) mobilizava-se contra o trabalho forçado (ESTERCI; FIGUEIRA, 2007, p. 87). Enfim discutido de forma mais sistematizada, o fenômeno passou a ser objeto das estatísticas. 
Dados oficiais de 1995 até 22 de maio de 2013, compilados pelo Ministério do Trabalho e Emprego (MTE), revelam que 46.478 trabalhadores foram encontrados pela fiscalização federal do trabalho em condições análogas à de escravidão, dela sendo "resgatados”, isto é, libertados (BRASIL, 2013b). Em 2014 e 2015, foram flagradas nessa condição, respectivamente, 1.752 e 1.010 pessoas (BRASIL, 2014, 2016).

Recentemente, a Divisão de Fiscalização para Erradicação do Trabalho Escravo (Detrae) do MTE realizou uma análise sobre o perfil das vítimas encontradas em condições análogas à de escravo, apenas com dados de fiscalizações do ano de 2015. Aferiu-se que o principal perfil das vítimas é o de jovens do sexo masculino, com baixa escolaridade e que migraram dentro do País, sobretudo oriundos dos estados da Bahia, do Maranhão e de Minas Gerais (BRASIL, 2015b). Há ocorrência da violação em estabelecimentos rurais e urbanos, tendo-se que, a partir de 2013, os registros oficiais passaram a apontar a prevalência de flagrantes de trabalho escravo nas cidades, com destaque para os setores da construção civil (TRABALHO..., 2014).

No que tange ao trabalho escravo rural, pesquisa da OIT mostra que são as grandes empresas do setor do agronegócio que mais fazem uso de mão de obra escrava (COSTA, 2010). A situação não é diferente no setor da construção civil, com o envolvimento de sólidos conglomerados empresariais em flagrantes de escravidão contemporânea.

O cadastro de empregadores que tenham mantido trabalhadores em condições análogas à de escravo, também conhecido como lista suja do trabalho escravo, revela, em números, a realidade de empresas, fazendas, incorporadoras, construtoras, siderúrgicas, transportadoras e tantos outros que tem ou tiveram o trabalho escravo presente em sua produção.

Tal cadastro foi criado por portarias pelo MTE e passou a ser utilizado como fundamento para restrição do acesso de infratores ao sistema financeiro de crédito. A legalidade da instituição dessa lista está sendo posta à prova na Ação Direta de Inconstitucionalidade $n^{\circ} 5.209$, no bojo da qual foi concedida medida cautelar que suspendeu sua divulgação. Ao tempo da vigência dessa decisão suspensiva, as organizações não governamentais Repórter Brasil e Instituto do Pacto Nacional para a Erradicação do Trabalho Escravo (InPACTO) solicitaram, com base na lei de acesso à informação (Lei $\mathrm{n}^{\circ}$ 12.527/2012), que o MTE fornecesse os dados do cadastro, relativos ao período entre 2013 e maio de 2015, os quais foram divulgados sob a denominação lista de transparência sobre trabalho escravo contemporâneo no brasil (SAKAMOTO, 2016).

A permanência, até os dias de hoje, da escravidão no território nacional, não pode, entretanto, ser atribuída à ausência de legislação repressora, a saber. 


\section{O CONCEITO NORMATIVO DE TRABALHO ESCRAVO NO ORDENAMENTO JURÍDICO BRASILEIRO}

As formas contemporâneas de escravidão encontram-se reprovadas, pela Constituição Federal brasileira, em virtude, primeiramente, da salvaguarda dos direitos fundamentais à igualdade e à liberdade (art. 5º caput e I). De modo mais próximo, a escravidão é repudiada pelo direito fundamental ao livre exercício de qualquer trabalho, ofício ou profissão (art. 5º XIII) e pela proteção dos direitos fundamentais trabalhistas mais básicos, v.g. salário mínimo, limite de jornada de trabalho, períodos de descanso e proteção contra riscos de acidentes (art. $7^{\circ}$ e incisos). Essas previsões se desdobram do comando axiológico central de proteção irrestrita à dignidade humana, alçada ao status de fundamento da República (art. $1^{\circ}$, III).

A proteção constitucional do trabalho livre é corroborada e incrementada pelos tratados internacionais de direitos humanos relativos à proibição da escravidão. Agregam-se, pois, ao ordenamento jurídico nacional os conceitos estabelecidos pela Organização das Nações Unidas (ONU) e pela OIT, mediante a ratificação dos respectivos tratados pelo Brasil.

Neste passo, da Convenção sobre a Escravatura de 1926, atualizada pela Convenção Suplementar sobre a Abolição da Escravatura, do Tráfego de Escravos e das Instituições e Práticas Análogas à Escravatura de 1956 - ambas ratificadas pelo Brasil e promulgadas pelo Decreto $\mathrm{n}^{\circ}$

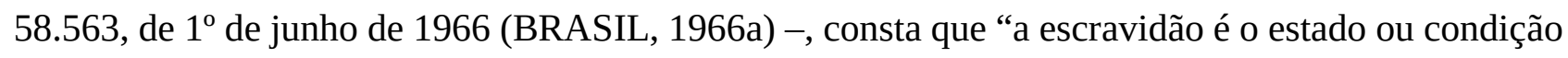
de um indivíduo sobre o qual se exercem, total ou parcialmente, os atributos do direito de propriedade” (art. $1^{\circ}$ da Convenção de 1926), havidas na adoção, entre outras, das práticas de servidão por dívidas ou por lei, costume ou acordo que obrigue alguém a trabalhar, contra a própria vontade, para outrem, com paga ou não (art. $1^{\circ}$ da Convenção de 1956).

Adicionalmente, por força do Decreto n 41.721, de 25 de junho de 1957, integra a legislação nacional o conceito de "trabalho forçado ou obrigatório", forjado pela Convenção $\mathrm{n}^{0} 29$ da OIT, de 1930, e que compreende "todo trabalho ou serviço exigido de uma pessoa sob a ameaça de sanção e para o qual não se tenha oferecido espontaneamente” (BRASIL, 1957). Em reforço a essa norma, adveio a Convenção $n^{\circ} 105$ da OIT, de 1957, promulgada, no Brasil, pelo Decreto ${ }^{\circ}$ 58.822, de 14 de julho de 1966 (BRASIL, 1966b).

Na legislação pátria, há o conceito do art. 149 do Código Penal, instituído pelo Decreto-Lei $\mathrm{n}^{\circ}$ 2.848, de 1940, quando tipificou o crime de redução a condição análoga à de escravo nestes termos: “Reduzir alguém a condição análoga à de escravo: pena - reclusão, de dois a oito anos” (BRASIL, 1940). Alteração legislativa de 2003 atribuiu ao dispositivo a seguinte redação: 
Art. 149. Reduzir alguém a condição análoga à de escravo, quer submetendo-o a trabalhos forçados ou a jornada exaustiva, quer sujeitando-o a condições degradantes de trabalho, quer restringindo, por qualquer meio, sua locomoção em razão de dívida contraída com o empregador ou preposto: (Redação dada pela Lei $n^{0} 10.803$, de 11.12.2003)

Pena - reclusão, de dois a oito anos, e multa, além da pena correspondente à violência $\S 1^{\circ}$ Nas mesmas penas incorre quem:

I - cerceia o uso de qualquer meio de transporte por parte do trabalhador, com o fim de retêlo no local de trabalho;

II - mantém vigilância ostensiva no local de trabalho ou se apodera de documentos ou objetos pessoais do trabalhador, com o fim de retê-lo no local de trabalho.

$\S 2^{\circ}$ A pena é aumentada de metade, se o crime é cometido:

I - contra criança ou adolescente;

II - por motivo de preconceito de raça, cor, etnia, religião ou origem (BRASIL, 2003).

A comparação entre os enunciados original e modificado desse artigo denotam a ampliação do espectro de proteção do tipo penal, em especial para alcançar situações outras que não apenas aquelas que suscitem o cerceamento da liberdade de ir e vir, demonstrando sensibilidade à exigência de atualização dos instrumentos normativos de proteção em face das complexas dinâmicas produtivas próprias dos tempos de hoje. A busca por uma atualização conceitual desponta como tendência mundial, como se poderá concluir a seguir.

\section{O CONCEITO DE TRABALHO ESCRAVO EM EXEMPLOS DE DIREITO COMPARADO}

\subsection{CASO PROSECUTOR VERSUS KUNARAC ET AL.}

O caso Prosecutor versus Kunarac et al. diz respeito ao julgamento de Dragoljub Kunarac, Radomir Kovac e Zoran Vukovic, que estiveram envolvidos em conflito armado, ocorrido entre 1992 e 1993, na cidade de Foča, na Bósnia e Herzegovina. Tal conflito se inseriu no contexto da guerra que teve lugar entre 1992 e 1995, permeada pelo enfrentamento étnico que marcou o esfacelamento da antiga Iugoslávia. Kunarac e os demais réus, todos de origem sérvia, foram acusados e condenados pelo envolvimento em mortes, estupros, tortura e escravização, praticados contra os habitantes não sérvios da região, especialmente os bósnios muçulmanos.

No que tange ao trabalho escravo, os acusados foram condenados pela câmara de primeira instância do Tribunal Internacional para a antiga Iugoslávia ${ }^{1}$, tendo havido apelação para uma câmara recursal. A defesa argumentou que a culpa pelo crime de escravização presume o tratamento da vítima como se ela fosse sua propriedade, a ausência de consentimento constante e claro da vítima durante

\footnotetext{
${ }^{1}$ O Tribunal Penal Internacional para a antiga Iugoslávia, com sede em Haia, Países Baixos, foi estabelecido em 25 de maio de 1993, em cumprimento à Resolução n. 827 do Conselho de Segurança da ONU, com o objetivo de julgar os crimes cometidos durante os conflitos bélicos ocorridos na região da ex-Iugoslávia.
} 
sua detenção e a submissão da vítima à situação de escravidão por um período de tempo indefinido ou pelo menos de forma prolongada. Além disso, alegou que existe um elemento intencional (denominado mens rea) no crime de escravidão, o qual indica que deve ser provada a intenção do agente em manter a vítima sob seu controle por um período prolongado de tempo. Com base em tais premissas, aduziu-se que nenhum dos elementos constitutivos do crime de escravidão foram satisfatoriamente provados (ORGANIZAÇÃO DAS NAÇÕES UNIDAS, 2002, p. 33-34).

A decisão da câmara recursal seguiu a tese da primeira instância, segundo a qual o conceito de escravidão, conforme definido pelo já citado art. $1^{\text {0 }}$ da Convenção sobre a Escravatura de 1926, contemporaneamente, comporta uma série de condutas que vão além da escravidão clássica, proibida em virtualmente todos os países. Entendeu-se que o exercício sobre algum indivíduo de todo ou qualquer atributo do direito de propriedade pode ou não estar ligado ao conceito de escravidão clássico, mas em todos os casos há alguma destruição da personalidade jurídica da vítima (ORGANIZAÇÃO DAS NAÇÕES UNIDAS, 2002, p. 35).

É importante notar que o Tribunal não toma a escravidão como fato descrito em lei, mas como condição. Cumpre, nessa linha, ao julgador identificar, no caso concreto, se foram exercidos sobre outra pessoa algum ou todos os atributos ligados ao direito de propriedade.

Além disso, o Tribunal considerou que, para se concluir que determinada conduta representa uma forma de escravização, deve haver a análise da presença de alguns fatores ou "indícios de escravização" (indicia of slavement, no texto original). Em linhas gerais, a câmara recursal mencionou alguns dos fatores já citados no julgamento em primeira instância, sendo eles “controle da movimentação do indivíduo, controle do ambiente, controle psicológico, medidas para prevenir ou deter fugas, sujeição a tratamento cruel, trabalho forçado” (ORGANIZAÇÃO DAS NAÇÕES UNIDAS, 2002, p. 36) e outros. A câmara recursal apresenta, sob essa ótica, o entendimento de que não há como serem enumeradas, exaustivamente, todas as formas contemporâneas de escravidão.

Não obstante a relevância de se declarar desapego ao conceito clássico de escravidão, descartando, a esse propósito, a perquirição do consentimento da vítima, assim considerando características mais atuais de exploração, a decisão do Tribunal, ao denotar a indispensabilidade da prova da manifesta intenção patronal de controle, acaba por atrelar o resultado do julgamento à existência de óbice à autonomia da vítima de se desligar da situação de sujeição.

\subsection{CASO R. VERSUS TANG}

O caso R. versus Tang diz respeito ao julgamento de Wei Tang, proprietária de um prostíbulo 
em Melbourne, Austrália, condenada a dez anos de prisão por submeter cinco mulheres tailandesas a condição de escravas. Apurou-se que as vítimas trabalhavam no prostíbulo para saldar dívida de A\$ 45.000,00 (quarenta e cinco mil dólares australianos) e o faziam seis dias por semana, com abatimento de A\$ 50,00 (cinquenta dólares australianos) por cliente atendido. Às mulheres foram fornecidas comida e acomodação, sem que houvesse encarceramento propriamente dito. Contudo, passaportes e passagens das vítimas foram confiscados e poucas eram as oportunidades de saída do estabelecimento de trabalho (AUSTRÁLIA, 2008, p. 7-10).

Tang apelou da decisão de primeira instância e a Suprema Corte do estado de Victoria (segundo grau de jurisdição) ordenou um novo julgamento, sob o argumento de inadequação da análise do elemento "intencionalidade", apontada como essencial à configuração do crime de escravidão. Dessa decisão apelou a acusação à Suprema Corte australiana, a qual, por sua vez, reformou o decidido pela Suprema Corte do estado de Victoria, tendo Tang, desse terceiro decisum, interposto "recurso subordinado" (cross appeal, no texto original). Nesse apelo, Tang questionou a constitucionalidade da definição e do escopo dos crimes de escravidão previstos no código penal australiano, bem como a razoabilidade da decisão adotada. O recurso de Tang não foi provido.

O código penal australiano apresenta definição de trabalho escravo praticamente idêntica ao conceito enunciado na Convenção de 1926, razão pela qual a Corte australiana, na análise deste caso, definiu trabalho escravo à luz da referida Convenção e dos seus trabalhos preparatórios (AUSTRÁLIA, 2008, p. 10-13).

Ante os questionamentos de Tang, o ministro Gleeson, presidente da Suprema Corte australiana, buscou elucidar o conteúdo da definição legal de escravidão disposta no artigo 270.1 do código penal australiano, que dispõe que escravidão é a condição de um indivíduo sobre o qual se exercem todo ou qualquer dos atributos ligados ao direito de propriedade, incluindo as situações em que tal condição resulte de uma dívida ou contrato realizado pelo agente ${ }^{2}$. O ministro, em seu exercício hermenêutico, considerou, para fins de caracterização do ilícito, três elementos ou atributos: a distinção entre escravidão de jure e escravidão de facto, os indícios da escravização e o papel do consentimento da vítima (AUSTRÁLIA, 2008, p. 11-14).

Motivado especificamente pelo argumento de Tang de que a escravidão se limita ao seu conceito clássico, o ministro, de saída, distingue escravidão de jure e de facto - ou, conforme a linguagem da Convenção de 1926 sobre a escravatura, a distinção entre estado e condição de escravo.

\footnotetext{
${ }^{2}$ Eis a redação original do art. 270 do código penal australiano: “270.1 Definition of slavery. For the purposes of this Division, slavery is the condition of a person over whom any or all of the powers attaching to the right of ownership are exercised, including where such a condition results from a debt or contract made by the person” (AUSTRÁLIA, 2016).
} 
Enquanto a escravidão de jure se dá em função de um direito de legalmente ter propriedade sobre determinada pessoa, a escravidão de facto (ou como condição) seria evidenciada por uma situação em que se verifica o exercício de um ou todos os direitos ligados à propriedade sobre um indivíduo.

O ministro argumentou que limitar o escopo da escravidão ao seu histórico conceito de escravidão de jure não guarda consistência com o contexto e com os propósitos da Convenção de 1926, até porque, ao tempo da gênese da Convenção, vários dos Estados que a aprovaram não reconheciam legalmente a escravidão. O julgador aduziu, ainda, que a Convenção buscou a vedação da escravidão de jure em todos os lugares e que o termo “estado ou condição” traz, de forma clara, a distinção proposta.

Prosseguiu o ministro presidente examinando o direito de propriedade e seus atributos, propondo-se a entender quais são os indícios de escravização, ao identificar, objetivamente, qual é o alcance do exercício de todos ou qualquer daqueles atributos.

A esse respeito, o ministro presidente Gleeson e o ministro Hayne apresentaram argumentos divergentes sobre o assunto. O ministro Gleeson considerou que os indícios de escravização podem ser analisados de acordo com a conduta do acusado, ou seja, deve-se perquirir a extensão do exercício dos atributos ligados ao direito de propriedade pelo réu. Para isso, Gleeson menciona os indícios apresentados no já analisado caso Prosecutor versus Kunarac et al., com destaque para ações como controle da movimentação e do ambiente em que as vítimas da escravização se encontram, controle psicológico, medidas tomadas para conter ou prevenir fugas, sujeição a tratamento cruel e sujeição a trabalhos forçados. Além disso, com base em um memorando de 1953 do Secretário Geral da ONU, Gleeson identificou que se incluem no direito de propriedade a capacidade de transformar uma pessoa em objeto de venda e compra, a capacidade de usar determinada pessoa e seu labor de forma irrestrita e a percepção dos frutos do trabalho de um indivíduo sem a devida contraprestação.

Já o ministro Hayne considerou os atributos do direito de propriedade sob o ponto de vista da autonomia da vontade da vítima (possibilidade de escolha sobre prestar ou não os serviços), ou seja, a escravidão deve ser examinada a partir de sua antítese: a liberdade. Sob esse prisma, há que se observar o escravo e não quem escraviza. Entendeu, pois, Hayne, que Tang exerceu o direito de propriedade sobre as vítimas, considerando o aspecto transacional da situação dessas e a restrição de seus movimentos (AUSTRÁLIA, 2008, p. 38-41).

Ambos os ministros concordaram não haver, para a configuração do crime, a exigência da prova de que o acusado tinha pleno conhecimento do exercício do direito de propriedade sobre as 
vítimas, bastando a sua capacidade de se valer dessas como se mercadoria fossem. Quanto ao papel do consentimento, aquiesceram os ministros que sua ausência não é elemento indispensável da escravidão. A condenação de Tang, então, manteve-se à unanimidade.

É digno de nota o exercício analítico realizado pela Suprema Corte australiana, ao estabelecer a distinção entre a escravidão de jure e a de facto, enquanto recurso teórico de atualização do conceito de escravidão consagrado pela Convenção da ONU de 1926, a permitir o alcance das formas hodiernas de exercício do direito de propriedade sobre outrem. Por outro lado, embora orientada por um propósito evolutivo, a noção de escravidão de facto mantém o atributo da liberdade de locomoção como protagonista da configuração do trabalho escravo.

\subsection{O MODERN SLAVERY ACT 2015 DO REINO UNIDO}

Em 26 março de 2015, o Parlamento inglês aprovou o Modern Slavery Act (MSA), com o intento de introduzir uma lei clara e moderna, que venha fazer frente ao trabalho escravo e ao tráfico de pessoas, no âmbito do Reino Unido. As notas explicativas que acompanham a lei mostram que sua aprovação resultou de reação do governo inglês às múltiplas formas assumidas pela escravidão nos dias de hoje e ao crescente fenômeno do tráfico de pessoas. Tais notas ainda fazem menção à Convenção de 1926 sobre a escravatura, às Convenções n ${ }^{\circ} 29$ (sobre trabalho forçado) e 182 (sobre a proibição das piores formas de trabalho infantil e a ação imediata para sua eliminação) da OIT e ao artigo $4^{\circ}$ da Convenção Europeia de Direitos Humanos (que proíbe a escravatura e o trabalho forçado), instrumentos normativos internacionais dos quais o Reino Unido é signatário (REINO UNIDO, 2015b).

O MSA desponta como interessante documento legislativo de direito interno que disciplina, mais detalhadamente, a proibição de todas as formas contemporâneas de escravidão e do tráfico de pessoas. Essa norma estabelece a capitulação do crime de escravidão, servidão ou trabalho forçado ou compulsório e do crime de tráfico de pessoas, além de capitular penas cabíveis, prever o confisco dos instrumentos encontrados no local do crime e admitir a possibilidade de indenização à vítima. Aliás, o MSA apresenta um capítulo inteiro dedicado à proteção das vítimas e auxílio em questões empregatícias e relacionadas à imigração.

Conquanto tenha o Reino Unido editado uma lei sensível ao fenômeno do trabalho escravo contemporâneo, pensa-se que a definição dada pelo documento não contém avanços conceituais em relação àqueles já previstos pelas principais convenções internacionais sobre o tema. 
É que o art. 1(1) do MSA ${ }^{3}$ capitula o crime de escravidão, servidão e trabalho forçado ou compulsório e dispõe, em sua alínea $a$, configurar-se o crime se a pessoa sujeita outra pessoa à escravidão ou servidão e as circunstâncias são tais que a pessoa saiba ou deva saber que a outra está sujeita à escravidão ou servidão. Conforme a alínea $b$ do mesmo dispositivo, há crime, igualmente, se a pessoa exige de outra pessoa a realização de trabalho forçado ou compulsório e as circunstâncias são tais que a pessoa saiba ou deva saber que à outra está sendo exigida a realização de trabalho forçado ou compulsório (REINO UNIDO, 2015a, p. 1).

O art. 1(2) do MSA ${ }^{4}$ diz que a definição de escravidão, servidão e trabalho forçado ou compulsório deve ser interpretada conforme o art. $4^{\circ}$ da Convenção Europeia de Direitos Humanos de 1950, que dispõe que (4.1) ninguém pode ser mantido em escravidão ou servidão e que (4.2) ninguém pode ser constrangido a realizar um trabalho forçado ou obrigatório (CONSELHO DA EUROPA, 2001, p. 5). Por fim, o art. 1(3) 5 estabelece que será dada atenção a todas as circunstâncias do caso para se determinar se a pessoa está sendo sujeita à escravidão ou servidão ou se a ela se está exigindo trabalho forçado ou compulsório.

As primeiras disposições do citado artigo vinculam a ocorrência da escravidão à percepção que o escravagista tem ou deveria ter sobre a condição da vítima, aproximando a descrição à concepção clássica de escravidão e, com isso, limitando a caracterização do ilícito. Já a disposição que, adicionalmente, adota a definição do art. $4^{\circ}$ Convenção Europeia de Direitos Humanos representa ampliação do alcance da proteção, em comparação com os demais dispositivos do MSA. Ocorre que o modo como a Corte Europeia de Direitos Humanos interpreta esse mesmo artigo tem sido um tanto restritivo, conforme adiante salientado.

\subsection{A CONFIGURAÇÃO DO TRABALHO ESCRAVO SEGUNDO A CORTE EUROPEIA DE DIREITOS HUMANOS E O CASO SILIADIN VERSUS FRANÇA}

A Corte Europeia de Direitos Humanos (CEDH) é o órgão jurisdicional do Sistema

\footnotetext{
${ }^{3}$ Na redação original, diz o artigo 1(1) do MSA: "Slavery, servitude and forced or compulsory labour (1) A person commits an offence if - (a) the person holds another person in slavery or servitude and the circumstances are such that the person knows or ought to know that the other person is held in slavery or servitude, or (b) the person requires another person to perform forced or compulsory labour and the circumstances are such that the person knows or ought to know that the other person is being required to perform forced or compulsory labour" (REINO UNIDO, 2015a).

${ }^{4} \mathrm{Na}$ redação original, diz o artigo 1(2) do MSA: "In subsection (1) the references to holding a person in slavery or servitude or requiring a person to perform forced or compulsory labour are to be construed in accordance with Article 4 of the Human Rights Convention." (REINO UNIDO, 2015a)

${ }^{5}$ Na redação original, diz o artigo 1(3) do MSA: "In determining whether a person is being held in slavery or servitude or required to perform forced or compulsory labour, regard may be had to all the circumstances." (REINO UNIDO, 2015a)
} 
Regional Europeu de Proteção dos Direitos Humanos, erigido a partir da Convenção Europeia de

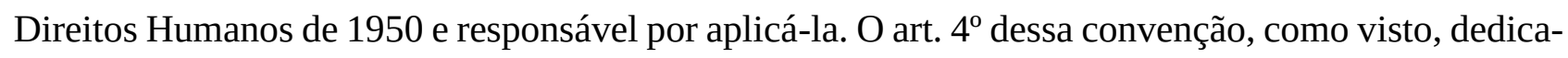
se a tipificar a escravidão, a servidão e o trabalho forçado.

De acordo com o Guia Interpretativo do artigo $4^{\circ}$ da Convenção Europeia de Direitos Humanos, que se baseia precipuamente nos casos julgados pela CEDH, o conceito de "escravidão" guarda identidade com a definição prevista na Convenção de 1926 sobre a escravatura (CONSELHO DA EUROPA, 2014, p. 7). Com relação à servidão, a CEDH a concebe como uma obrigação de oferecer serviços a outrem imposta pelo uso de coerção e, quanto ao trabalho forçado ou compulsório, considerando a ausência de definição explícita do termo, a Corte Europeia entende que a Convenção busca inspiração no conceito oferecido pelo art. $2^{\circ}$ da Convenção ${ }^{\circ} 29$ da OIT, segundo o qual, relembre-se, trabalho forçado é o "trabalho ou serviço exigido de um indivíduo sob ameaça de qualquer penalidade e para o qual ele não se ofereceu de espontânea vontade.” (CONSELHO DA EUROPA, 2014, p. 7-8)

A CEDH, em seu Guia Interpretativo, faz referência ao caso Siliadin versus França, julgado em 2005. Em 1994, aos quinze anos, Siwi-Akofa Siliadin foi trazida do Togo à França por uma cidadã francesa de origem togolesa, referida na decisão como “Senhora D.” A Senhora D. e seu marido, após confiscarem o passaporte de Siliadin, submeteram-na a trabalho forçado e não remunerado no âmbito doméstico, além de a “emprestarem” a um casal de amigos (identificados na decisão como "Senhora e Senhor B.”), para que os ajudasse com tarefas domésticas e cuidados com uma criança. Nessa situação, a menina trabalhou das 07h30min às 22h30min, diariamente, sem direito a dia de folga, dormindo em um colchão no chão e usando roupas velhas (CONSELHO DA EUROPA, 2005, p. 29).

Em 1998, Siliadin confidenciou sua situação a um vizinho, que informou o caso ao Comitê contra Escravidão Moderna da ONU em Paris, o qual, por sua vez, reportou-se ao Ministério Público. Na França, a Senhora e o Senhor B. foram condenados, em primeira instância, a doze meses de prisão por exploração indevida de vulnerável, logrando absolvição em segunda instância. Em 2003, o caso foi levado à Corte de Apelação de Versalhes, ocasião em que os réus foram considerados culpados por submeter Siliadin a situação de trabalho não remunerado, embora se tenha considerado que as condições de vida e trabalho oferecidas não eram incompatíveis com a dignidade humana. Houve condenação também ao pagamento de pouco mais de $€ 15.000,00$ (quinze mil euros) para compensar os danos causados à menina.

Embora o caso estivesse sob análise do judiciário da França, em 2001 Siliadin peticionou 
perante a CEDH, sob a alegação de que a lei penal francesa não oferecia proteção suficiente e efetiva contra a servidão à qual foi submetida ou, pelo menos, à submissão a trabalho forçado e compulsório, que a teria tornado uma escrava doméstica. Entre maio e junho de 2005 foi prolatada a sentença definitiva da CEDH. Ao longo do julgamento, além da narrativa dos fatos, a Corte dedicou um tópico inteiro da sentença para indicar a legislação relevante para a análise do caso, à qual o Estado francês está submetido, notadamente o código penal francês, um relatório da Assembleia Nacional francesa, documentos emitidos pelo Conselho da Europa e convenções internacionais sobre o assunto.

Após considerar que a violação por qualquer Estado ao art. $4^{\circ}$ da Convenção Europeia de Direitos Humanos pode ocorrer mesmo sem a ação direta de um agente estatal, bastando a constatação de que não foram tomadas medidas no sentido de adotar leis criminais que punam o crime de escravidão ou servidão, a Corte passou a debater o alcance da alegada afronta ao artigo. A CEDH observou grande similaridade entre o parágrafo $3^{\circ}$ do art. $4^{\circ}$ da Convenção Europeia de Direitos Humanos e o parágrafo $2^{\circ}$ do art. $2^{\circ}$ da Convenção $n^{\circ} 29$ da OIT - pois ambos contemplam hipóteses que não representam trabalho forçado ou obrigatório -, tendo, ainda, invocado como parâmetro o art. $2^{\circ}$ da Convenção n ${ }^{\circ} 29$ da OIT (CONSELHO DA EUROPA, 2005, p. 26-30).

Quanto à ameaça de sanção, a Corte entendeu que a situação pressupunha coação, embora não explícita, visto que a vítima vinha de outro país, estava ilegalmente em território francês e por isso tinha medo de ser presa pela polícia. Quanto ao segundo elemento - trabalho para o qual não se tenha oferecido espontaneamente -, a Corte inferiu dos fatos que Siliadin não realizou os serviços de modo espontâneo, tendo-os prestado por falta de opção, a configurar a hipótese do art. $4^{\circ}$ da Convenção Europeia (CONSELHO DA EUROPA, 2005, p. 31).

A CEDH, então, cita a definição de escravidão disposta na Convenção de 1926 sobre a escravatura; no entanto, identifica-a como modalidade de escravidão clássica. A decisão afirma que Siliadin, ainda que privada de sua autonomia, não foi submetida à escravidão per se, ou seja, não foi reduzida ao status de um objeto. Quanto à servidão, a CEDH, conforme sua jurisprudência, a toma por séria negação à liberdade, sendo requisito para sua configuração que a vítima preste serviços para outros, morando no local da prestação, sem a possibilidade de alterar tal condição. A Corte sustenta, ainda, que servidão, nos termos da Convenção Europeia de Direitos Humanos, significa uma obrigação de prover serviços, imposta por meio de coerção, estando ligada ao aludido conceito de escravidão. Por fim, conclui a Corte que Siliadin foi submetida a servidão e declara, como requereu a vítima, que a legislação francesa, de fato, não tutelou adequadamente a violação, caracterizando afronta ao art. $4^{\circ}$ da Convenção Europeia (a pretensão foi apenas declaratória, não tendo havido 
pedido de indenização).

A CEDH, portanto, adota, com base na Convenção Europeia de Direitos Humanos, marcada distinção entre trabalho escravo e servidão, tomando a primeira de modo mais alinhado à ideia clássica da escravidão. Em que pese tal distinção significar ampliação das formas de exercício dos direitos de propriedade sobre outrem, notadamente em vista da figura da servidão, também nessa o elemento privação de liberdade - mesmo que não integral ou explícita, mas inferida - protagoniza a configuração da prática; neste caso, inclusive, tendo sido decisivo para a condenação dos réus.

\section{O CONCEITO NORMATIVO BRASILEIRO DE TRABALHO ESCRAVO VIS-À-VIS OS CASOS INTERNACIONAIS ANALISADOS}

Infere-se das normas e julgados internacionais examinados que a figura da liberdade como bem juridicamente tutelado nos casos de trabalho escravo segue sendo central, especialmente a de locomoção. O principal referencial internacional ainda é a definição cunhada pela Convenção sobre a escravatura, de 1926 (atualizada em 1956), entretanto, com evidente apelo hermenêutico de ampliação, com vistas ao alcance das situações hodiernas mais complexas de exercício dos atributos do direito da propriedade por uma pessoa sobre outra.

A doutrina produzida por Kevin Bales e Jean Allain, bastante conhecida na atualidade, é fiel representação da concepção de escravidão vinculada ao exercício dos poderes de propriedade sobre outrem, com finalidade de obtenção de proveito econômico. Sob tal inspiração e tendo por referência a multicitada Convenção sobre a escravatura da ONU, os referidos autores preceituam que o conceito de escravidão não pode prescindir de três elementos essenciais, quais sejam, o uso da violência, a habilidade (ou possibilidade) de controle sobre a vítima pela tomada de sua posse (the agency of the slave) e, em decorrência desse controle, a exploração econômica do outro (BALES; ALLAIN, 2012, p. 4).

Sob essa ótica e com ela consentânea, nos exemplos analisados, a preocupação com as formas contemporâneas de manifestação da escravidão se traduziram no reconhecimento de diversas circunstâncias indicativas de privação do direito de ir e vir das vítimas, que não apenas as que denotam claro aprisionamento da vítima. Percebe-se que a legislação e, notadamente, os tribunais internacionais, tem cada vez mais estendido a proteção jurídica a situações para além do ostensivo cerceamento da liberdade de locomoção, mediante coação direta, típico da visão clássica sobre o fenômeno.

Daí que situações como servidão por dívidas e jornadas laborais extensas passaram a ser 
consideradas como elementos que ajudam a retirar da vítima o integral controle de seu destino, atrelando-o à vontade do contratante e assim evidenciando o exercício, em face do escravizado, dos atributos inerentes ao direito de propriedade.

Afigura-se, sob tal contexto, louvável a consideração das condições a que estão submetidos os trabalhadores, porquanto evidencia atenção para com as formas atuais de exploração do labor alheio. Todavia, pensa-se que os exemplos apresentados ainda fazem com que a análise dessas condições gravite em torno da obrigatoriedade de demonstração do poder integral ou parcial de decisão do empregador sobre os destinos do seu empregado. Precisamente neste ponto a atual normativa brasileira mostra-se sobremaneira mais avançada.

Exsurgem da redação vigente do art. 149 do Código Penal quatro modalidades de trabalho análogo ao de escravo: trabalho forçado; trabalho em jornada exaustiva; trabalho em condições degradantes; e trabalho com restrição de locomoção em razão de dívidas. Note-se que todas as modalidades estão agrupadas sob o tipo penal “trabalho análogo ao de escravo”, não se reforçando, com isso, a diferenciação que se percebe, por exemplo, no MSA britânico e na interpretação conferida pela CEDH à Convenção Europeia de Direitos Humanos.

A inclusão do trabalho degradante como uma das elementares do tipo penal sob exame serviu, sem dúvida, à expansão do horizonte de proteção da norma. Segundo Viana (2006, p. 200), há cinco hipóteses de tipificação de trabalho degradante caracterizador de escravidão: (i) a falta explícita de liberdade, ainda que ausente a figura do fiscal armado ou outra ameaça de violência, haja vista que uma dívida impagável pode tolher a liberdade do trabalhador; (ii) a própria jornada exaustiva (extensa ou intensa), assim como o poder diretivo exacerbado, o assédio moral e situações análogas; (iii) o pagamento de salário aquém do mínimo legal ou reduzido por descontos ilegais; (iv) a exposição da saúde do trabalhador a risco inaceitável, tal qual o fornecimento de água insalubre, de alimentação estragada ou insuficiente e, no caso de alojamento propiciado pelo empregador, a disponibilização de barraca de plástico ou a não disponibilização de colchões ou lençóis; e (v) o trabalhador levado pelo empregador a residir em moradia sem mínimas condições adequadas e sem que ao obreiro seja franqueada opção diferente dessa.

Em assim sendo, a comparação entre os enunciados original e modificado do art. 149 denota a ampliação do espectro de proteção do tipo penal, em especial para alcançar situações outras que não apenas aquelas que coíbam a liberdade de ir e vir. A esse respeito, é crucial perceber que a redação atual daquele artigo não confere protagonismo à restrição de locomoção em vista das demais situações que enuncia. Ao contrário, haverá trabalho escravo se verificadas, individualmente (e não 
cumulativamente), quaisquer das modalidades arroladas.

Como esclarece Brito Filho (2012, p. 101-102), a alteração do tipo penal brasileiro “produziu mudança significativa a respeito do bem jurídico principalmente protegido, que passou da liberdade para o atributo maior do homem, que é a sua dignidade, na versão contemporânea, e que é baseada na visão e fundamentação que lhe emprestou Kant”.

Há que se compreender que a passagem da proteção da liberdade à salvaguarda da dignidade responde a uma urgência histórica de recuperação da força jurídica dos preceitos antiescravagistas, em face à complexidade atual das formas mais vis de exploração da mão de obra, as quais, no mais das vezes, ainda que sem fazer uso da limitação de locomoção, conduzem o ser humano às condições mais indignas de existência, afrontando sobretudo sua saúde física e mental.

Nessa linha, o exercício dos atributos do direito de propriedade, hoje mais do que antes, manifesta-se de modo dissimulado, mediante submissão do trabalhador a jornadas extenuantes e a riscos desarrazoados (presentes em ambientes desmesuradamente insalubres, perigosos ou penosos), na falta de fornecimento de equipamentos básicos de proteção individual e coletiva, na disponibilização inadequada de alimentação, no oferecimento de alojamentos degradados, entre outros fatores. Enfim, trata-se do exercício da propriedade (uso, gozo, fruição, disposição) em face da saúde física e mental, do tempo disponível para as relações sociais e da remuneração do trabalhador, superando, por conseguinte, a ideia exclusiva de dominação do ir e vir da vítima, que permanece tutelada.

Nos termos em que foi atualizada, a normativa brasileira colocou-se um passo adiante do que parece ainda ser a tendência internacional de atrelar a escravidão apenas à proibição, mesmo que parcial, da locomoção. O exemplo brasileiro é louvado pela comunidade internacional.

Prova disso é o conteúdo de publicação de nota oficial sob a forma de "artigo técnico", em 2016, pela ONU, mediante o qual recomenda a rejeição, pelo Congresso Nacional brasileiro, do Projeto de Lei do Senado $n^{\circ}$ 432/2013 (BRASIL, 2013c), proposto visando regulamentar o art. 243 da Constituição Federal, o qual, após a alteração promovida pela Emenda Constitucional $n^{\circ}$ 81, de 5 de junho de 2014 (EC 81/14), passou a admitir a expropriação sem indenização e destinação à reforma agrária de propriedades rurais e urbanas onde for constatada a ocorrência de trabalho análogo ao de escravo. Com vistas a amenizar os efeitos práticos da EC 81/14, o projeto de lei propõe nova conceituação de trabalho escravo para fins de expropriação, arrefecendo o tipo descrito no art. 149 do Código Penal, por contemplar apenas casos de trabalho forçado e de servidão por dívida, excluindo as condições degradantes e a jornada exaustiva. 
No artigo técnico, a ONU afirma que, com a nova redação do art. 149 do Código Penal, o País introduziu "um conceito moderno de trabalho escravo, alinhado com as manifestações contemporâneas do problema, que envolve não só a restrição de liberdade e a servidão por dívidas, mas também outras violações da dignidade da pessoa humana” (ORGANIZAÇÃO DAS NAÇÕES UNIDAS, 2016, p. 5, grifo do autor), mencionando, inclusive, o fato de esse conceito ser adotado como referência legislativa pela OIT. A postura legislativa brasileira é qualificada como destacada, no cenário contemporâneo, por mirar a proteção da dignidade do trabalhador, reconhecendo que o trabalho escravo "perpassa a noção de mera ausência de liberdade” e transformando, bem por isso, sua legislação em "base para a atuação de diversos outros países que desejarem combater mais efetivamente o crime” (ORGANIZAÇÃO DAS NAÇÕES UNIDAS, 2016, p. 5).

Constata-se, ainda, que a atualização da redação do art. 149 do Código Penal demonstra que o Brasil se antecipou a um movimento internacional de expansão da proteção contra a escravidão, em especial pela atualização do tratamento jurídico de suas formas contemporâneas de manifestação, movimento esse capitaneado pela OIT e formalizado, em termos normativos, com o Protocolo Relativo à Convenção sobre Trabalho Forçado, de 1930.

No ano de 2014, a Conferência Internacional da OIT aprovou, unanimemente, o Protocolo Relativo à Convenção sobre Trabalho Forçado de 1930, corroborado pela Recomendação n 203 , aprovada na mesma ocasião (ORGANIZAÇÃO INTERNACIONAL DO TRABALHO, 2014, p. 131140), com vistas a atualizar sua Convenção $\mathrm{n}^{\circ} 29$. O art. $2^{\circ}, f$, do Protocolo afirma que as medidas estatais para coibir o trabalho forçado deverão incluir ações para tratar as causas profundas e os fatores que aumentam o risco de trabalho forçado. De seu turno, a Recomendação $\mathrm{n}^{\circ} 203$ explicita estarem os Estados-membros da OIT obrigados a examinar as causas geradoras das vulnerabilidades que favorecem a escravização de trabalhadores (art. $4^{\circ}, a$ ), bem como a adotar medidas que garantam o cumprimento das leis trabalhistas por todos os setores da economia (art. $4^{\circ}, e$ ). Tais disposições deixam assente o viés ampliativo da proteção jurídica perseguida por ambas as normas de 2014.

O Brasil, portanto, conta com uma previsão legal que contempla, de modo explícito e inequívoco, um conceito de escravidão cuja amplitude só poderá ser atingida, nas esferas internacionais, por meio de esforço hermenêutico, à vista dos enunciados das normas vigentes.

É dizer, precisamente porque estabelece a dignidade humana como bem juridicamente tutelado pela previsão de crime de redução ao trabalho análogo ao de escravo - fazendo-o para além da liberdade de locomoção, conquanto a proteja igualmente -, a legislação brasileira pode ser considerada avançada em matéria de conceituação das formas contemporâneas de escravidão, se 
comparada aos conceitos normativos encontrados em outros países e até mesmo em relação ao quanto preceituado pelas convenções da ONU e da OIT.

\section{A APLICAÇÃO DO CONCEITO NORMATIVO DE TRABALHO ESCRAVO PELA JURISPRUDÊNCIA BRASILEIRA}

Não obstante a considerável amplitude de proteção oferecida pelo conceito normativo brasileiro de trabalho escravo, a jurisprudência brasileira ainda mostra certo conforto em declarar havida escravidão quando evidenciado o cerceamento do direito de ir e vir, embora demonstre estar preparada para superar essa interpretação restritiva da norma.

A título ilustrativo, apresentam-se duas decisões judiciais sobre a matéria que experimentaram importante repercussão, proferidas no âmbito da Justiça do Trabalho, sabidamente sensível ao tema, no âmbito de ações civis públicas propostas pelo Ministério Público do Trabalho (MPT), buscando a tutela inibitória das práticas caracterizadoras da escravidão, pela via da imposição de obrigações de fazer e não fazer, bem como a reparação do dano moral coletivo advindo da gravidade da conduta.

A escolha específica dessas sentenças visa atender ao intuito de confrontar duas interpretações acerca da amplitude do atual conceito normativo brasileiro sobre escravidão, uma mais restritiva e outra mais ampliativa. Curiosamente, foram essas decisões proferidas por juízos do interior paulista, ambas contra grandes empresas da construção civil.

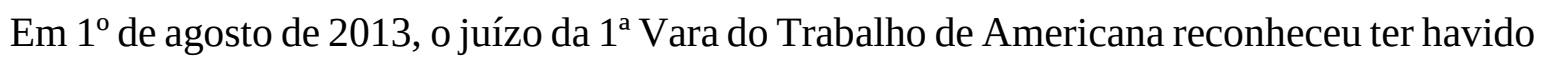
a redução a condição análoga à de escravos de 64 empregados que prestavam serviços, por interpostas pessoas jurídicas, à MRV Engenharia e Participações, impondo-lhe, por isso, além de obrigações de fazer e não fazer relativas às práticas repudiadas, a indenização por dano moral coletivo no importe de $\mathrm{R} \$ 4.000 .000,00$ (quatro milhões de reais). Consta do decisum:

Esses trabalhadores foram trazidos de regiões miseráveis do Norte e Nordeste com a promessa de que teriam a viagem inteiramente custeada pela empresa e que ganhariam um salário que, mesmo parecendo pouco para os padrões do Estado de São Paulo, seria bastante significativo.

A realidade, no entanto, mostrou-se completamente diferente. Ao desembarcarem na cidade de Americana foram informados que a dívida pela viagem seria descontada do salário de cada um. Entregaram suas carteiras de trabalho, na esperança da efetivação do registro, porém, os prepostos da ré se apossaram indevidamente dos documentos, retirando o livre arbítrio dos operários de não mais se sujeitarem à situação.

E não foi só. A empresa não pagava os salários combinados, e quando os pagava, ou estavam atrasados ou com descontos indevidos. Havia supressão total ou parcial do intervalo intrajornada, bem como a comida servida tinha de ser complementada pelos próprios operários, que gastaram todo o dinheiro que haviam guardado para a viagem. Os 
trabalhadores não tinham dinheiro para sair da cidade, por isso acabaram por ficar presos àquela situação até a data da denúncia perante o órgão do MTE. [...]

Como se vê, os funcionários laboravam em jornada exaustiva, tendo seu direito de locomoção tolhido pela ausência de pagamento e pela retenção da CTPS, o que pode ser definido como coerção moral, viciando a aquiescência da parte mais fraca. (BRASIL, 2013a, p. 16, grifo nosso)

Percebe-se que a decisão considera as condições degradantes de trabalho, relativas à falta de pagamento integral dos salários, ausência de intervalo intrajornada e sonegação de alojamento e alimentação adequados, contudo as articula de modo a tomá-las como elementos que ajudam a demonstrar o obstáculo ao direito de ir e vir.

Já a $2^{\text {a }}$ Vara do Trabalho de Araraquara foi palco da maior condenação pecuniária brasileira por utilização de trabalho escravo até o momento: cinquenta milhões de reais a título de reparação de dano moral coletivo. Foram rés na ação Norberto Odebrecht S.A., Odebrecht Serviços de Exportação S.A. e Odebrecht Agroindustrial, tendo respondido por aliciamento e tráfico internacional de pessoas, bem como redução de trabalhadores a condição análoga à de escravos em obras realizadas em Angola.

Argumentou a sentença, exarada em 28 de agosto de 2015, que o trabalho escravo constituise em "explorar o trabalho alheio, impondo qualquer forma de restrição da liberdade (não apenas da locomoção, mas de qualquer meio de interagir com outra pessoa), valendo-se da necessidade premente de subsistência dessa pessoa humana”, assim como submetendo-a a condições degradantes (a exemplo de jornadas exaustivas), transformando-a em objeto sem vontade ou personalidade, sendo certo que "a forma mais eficiente para impedir que a vítima saia do local de trabalho escravo é tirando seus documentos e proibindo o uso de transporte.” (BRASIL, 2015a, p. 14, grifo nosso)

Nesse excerto da decisão, o elemento liberdade de locomoção uma vez mais protagoniza a análise judicial. Todavia, mais adiante, a sentença romperá qualquer compromisso irrestrito com a demonstração do cerceamento do direto de ir e vir, abrindo-se para a ampliação da proteção propugnada pela atual redação do art. 149 do Código Penal brasileiro, ao pontuar que o trabalho escravo passou a ser gênero com duas espécies, quais sejam, o trabalho forçado e o trabalho degradante (BRASIL, 2015a, p. 14).

A decisão acena positivamente à dignidade humana como bem juridicamente tutelado pelo dispositivo penal em comento, fazendo-o de modo mais explícito na seguinte passagem, dedicada à interpretação do que seja trabalho degradante para fins de configuração do crime alusivo à escravidão contemporânea, razão da condenação:

Como já se ressaltou anteriormente, o trabalho degradante deve ser entendido pela conjugação de dois fatores: um factual, outro axiológico. O factual decorre da adequação de uma relação de trabalho concreta à disciplina legal incidente sobre tal relação, ou seja, o 
cumprimento pelo empregador dos direitos mínimos fixados pela legislação nacional, mesmo para trabalho no estrangeiro; o axiológico decorre do respeito ao conceito de dignidade humana, entendida como a conjunção dos valores de liberdade e de igualdade e vida. [...]

Neste contexto, é evidente que a conduta (omissão/negligência) das reclamadas ao não oferecerem condições adequadas de alojamento (higiene e saúde) no local de trabalho para cidadãos brasileiros que conduziu para Angola e em relação aos quais tinha ampla responsabilidade de guarda e de segurança, importou não apenas em descumprimento das normas mínimas de higiene, saúde e segurança do trabalho, em ofensa à NR-31, causando, também, humilhação e sofrimento íntimo, especialmente porque tais obreiros se encontravam longe de suas casas, provocando uma sensação de abandono, implicando em violação aos direitos fundamentais de um grupo de trabalhadores, atingindo princípios basilares do Estado Democrático de Direito preceituados na Constituição da República, dentre eles, os da dignidade da pessoa humana e dos valores sociais do trabalho (art. $1^{\circ}$, III e IV, da CF). (BRASIL, 2015a, p. 17)

A decisão do juízo da 2. ${ }^{a}$ Vara do Trabalho de Araraquara é exemplo de análise da violação da dignidade humana no caso concreto, valendo-se do fato de o conceito insculpido pelo art. 149 do Código Penal contemplar um conjunto de condutas que abarca um grande número de práticas comuns no contexto do trabalho escravo, tornando possível ao julgador identificar de forma profunda a degradação da pessoa escravizada.

A sentença capta a realidade mais perversa do trabalho escravo, não apenas pelo cerceio da liberdade, por manutenção de trabalhadores longe de seu local de origem, senão também pela afronta à vida, decorrente da oferta de alojamentos e ambiente de trabalho impróprios para qualquer ser humano. Essa perspectiva consagra a escravidão contemporânea como a incidência do exercício dos atributos da propriedade não apenas sobre a autonomia de ir e vir, mas igualmente sobre a vida e a saúde (física e mental).

\section{CONCLUSÃO}

A investigação de direito comparado, proposta por este trabalho, corrobora a posição de vanguarda do Brasil, no que se refere a conceito de trabalho escravo, estabelecido em lei.

De modo avançado em relação ao estágio normativo-jurisprudencial internacional, a definição legal brasileira de trabalho escravo encontra-se qualificadamente adequada ao enfrentamento das suas formas contemporâneas de manifestação, na medida em que elege a dignidade humana como bem juridicamente tutelado pela proibição da escravidão, ampliando o espectro protetivo para além da liberdade de locomoção, essência do direito de ir e vir.

O fato de a ONU e a OIT comungarem dessa percepção, já a tendo tornada pública, constitui importante confirmação da posição vanguardista do Brasil na matéria, o que não significa que o País esteja perto de erradicar essa aviltante forma de violação a direitos humanos, como demonstram as 
estatísticas oficiais.

Resta, pois, aos agentes estatais escudarem este aparato normativo dos naturais ataques. De um lado, fazendo-o valer em toda a sua potencialidade e rigor, quando da sua aplicação, sobretudo no que dispõe a respeito das outras modalidades de escravidão que não o já consagrado cerceamento do direito de ir e vir; de outro, pelo repúdio a qualquer proposta de mitigação ou arrefecimento da tipologia legal em vigor.

Não se perca de vista que a atual redação do art. 149 do Código Penal galgou a posição de eixo referencial para a configuração da escravidão não apenas para fins criminais, senão também para a definição de políticas públicas governamentais e, sobretudo, para fundamentar medidas repressivas por parte de agentes estatais administrativos, como os auditores-fiscais do trabalho, e por operadores do direito em instâncias não criminais, v.g. os membros do Ministério Público do Trabalho e os magistrados da Justiça do Trabalho.

Nesses termos, o ataque ao espectro amplo de proteção oferecido pelo conceito normativo em vigor certamente representará golpe fatal no instrumental jurídico que subsidia toda a estrutura estatal hoje voltada ao combate da escravidão contemporânea no Brasil.

Conquanto seja certo que o conceito normativo é mero instrumento de ação, cuja eficácia depende de fatores políticos e institucionais que permitam o seu manejo, é igualmente seguro que, se a norma não produz efeitos sozinha, que dirá se ela não existisse ou, existindo, não oferecesse tutela com a necessária amplitude.

\section{REFERÊNCIAS}

AUSTRÁLIA. Australian Government. Criminal Code Act 1995. Compilation No. 106. Atualizado em 7 jul. 2016. Disponível em: <https://goo.gl/ZiykAN>. Acesso em: 17 jul. 2016.

AUSTRÁliA. The High Court of Australia. The Queen v Wei Tang. Camberra, 28 de agosto de 2008. Disponível em: <https://goo.gl/X7RT9e>. Acesso em: 15 jul. 2016.

BALES, Kevin; ALLAIN, Jean. Slavery and its Definition. Queen's University Belfast Law Research Paper, $n$ 12-06. Global Dialogue, v. 14, n. 2. Irlanda do Norte, 2012. Disponível em: <https://goo.gl/Oxwez4>. Acesso em: 29 nov. 2016.

BRASIL. $1^{\text {a }}$ Vara do Trabalho de Americana. Sentença do Processo $n^{\circ}$ 0002084-28.2011.5.15.0007. Autor: Ministério Público do Trabalho da $15^{a}$ Região. Réu: MRV Engenharia e Participações. Juíza Sentenciante: Natália Scassiotta Neves Antoniassi. Americana, 1 de agosto de 2013 (2013a). Disponível em: <https://goo.gl/IJHao0>. Acesso em: 14 jul. 2016. 
BRASIL. $2^{\text {a }}$ Vara do Trabalho de Araraquara. Sentença do Processo n ${ }^{\circ}$ 0010230-31.2014.5.15.0079. Autor: Ministério Público do Trabalho da $15^{a}$ Região. Réus: Construtora Norberto Odebrecht e Outros. Juiz Sentenciante: Carlos Alberto Frigieri. Araraquara, 28 de agosto de 2015 (2015a). Disponível em: <https://goo.gl/c0TOu3>. Acesso em: 14 jul. 2016.

BRASIL. Constituição da República Federativa do Brasil, promulgada em 5 de outubro de 1988. Disponível em: <https://goo.gl/zaRrL>. Acesso em: 5 jul. 2016.

BRASIL. Decreto $\mathbf{n}^{\mathbf{0}}$ 41.721, de 25 de junho de 1957. Promulga as Convenções Internacionais do Trabalho de ${ }^{0} 11,12,13,14,19,26,29,81,88,89,95,99,100$ e 101, firmadas pelo Brasil e outros países em sessões da Conferência Geral da Organização Internacional do Trabalho. Disponível em: $<$ https://goo.gl/5rbLGX>. Acesso em: 5 jul. 2016.

BRASIL. Decreto $\mathbf{n}^{0}$ 58.563, de $1^{\circ}$ de junho de 1966 (1966a). Promulga a Convenção sobre Escravatura de 1926 emendada pelo Protocolo de 1953 e a Convenção Suplementar sobre a Abolição da Escravatura de 1956. Disponível em: <https://goo.gl/Z0zzZk>. Acesso em: 19 jul. 2016.

BRASIL. Decreto $\mathbf{n}^{\circ}$ 58.822, de 14 de julho de 1966 (1966b). Promulga a Convenção no 105 concernente à abolição do Trabalho forçado. Disponível em: <https://goo.gl/IOaGcG>. Acesso em: 5 jul. 2016.

BRASIL. Decreto-Lei $\mathbf{n}^{0}$ 2.848, de 7 de dezembro de 1940. Código Penal. Disponível em: $<$ https://goo.gl/HiYwJ1>. Acesso em: 5 jul. 2016.

BRASIL. Lei $\mathbf{n}^{\mathbf{0}} \mathbf{1 0 . 8 0 3}$, de 11 de dezembro de 2003. Altera o art. 149 do Decreto-Lei no 2.848, de 7 de dezembro de 1940 - Código Penal, para estabelecer penas ao crime nele tipificado e indicar as hipóteses em que se configura condição análoga à de escravo. Disponível em: $<$ https://goo.gl/L5KqJ>. Acesso em: 5 jul. 2016.

BRASIL. Ministério do Trabalho e Emprego. Inspeção do Trabalho resgatou 936 pessoas de trabalho escravo no Brasil em 2015. Brasília, 2015 (2015b). Disponível em: $<$ https://goo.gl/wwynQc>. Acesso em: 5 jul. 2016.

BRASIL. Ministério do Trabalho e Emprego. Quadro das operações de fiscalização para erradicação do trabalho escravo - SIT/SRTE 2015. Brasília, 2016. Disponível em: $<$ https://goo.gl/h3k4sB>. Acesso em: 5 jul. 2016.

BRASIL. Ministério do Trabalho e Emprego. Quadro das operações de fiscalização para erradicação do trabalho escravo - SIT/SRTE 2014. Brasília, 2014. Disponível em: $<$ https://goo.gl/A27i0X>. Acesso em: 5 jul. 2016.

BRASIL. Ministério do Trabalho e Emprego. Quadro geral das operações de fiscalização para erradicação do trabalho escravo - SIT/SRTE 1995 a 2013. Brasília, 2013 (2013b). Disponível em: $<$ https://goo.gl/SoV1lA>. Acesso em: 5 jul. 2016.

BRASIL. Senado Federal. Projeto de Lei do Senado $n^{0}$ 432, de 2013 (2013c). Dispõe sobre a expropriação das propriedades rurais e urbanas onde se localizem a exploração de trabalho escravo e dá outras providências. Disponível em: <https://goo.gl/3xH0F1>. Acesso em: 5 jul. 2016. 
BRITO FILHO, José Claudio Monteiro de. Dignidade da Pessoa Humana como fundamento para o combate ao trabalho em condições análogas à de escravo: a contribuição da $1^{\text {a }}$ Turma do Tribunal Superior do Trabalho no processo TRT-RR-178000-13.2003.5.08.0117. In: Revista do Tribunal Superior do Trabalho, v. 78, n. 3, jul/set 2012, p. 93-107. Disponível em: <https://goo.gl/5Zugcs>. Acesso em: 4 jul. 2016.

CONSELHO DA EUROPA. Convenção Europeia dos Direitos do Homem. Estrasburgo, França, 1 fev. 2001. Disponível em: <https://goo.gl/TpP8pA>. Acesso em: 14 jul. 2016.

CONSELHO DA EUROPA. Corte Europeia de Direitos Humanos. Case of Siliadin v. France. Estrasburgo, 26 de julho de 2005. Disponível em: <https://goo.gl/c61hbp>. Acesso em: 15 jul. 2016.

CONSELHO DA EUROPA. Corte Europeia de Direitos Humanos. Guide on Article 4 of the European Convention on Human Rights. 2. ed. Estrasburgo, 2014. Disponível em: $<$ https://goo.gl/eJk3Cc>. Acesso em: 13 jul. 2016.

COSTA, Patrícia Trindade Maranhão. Combatendo o trabalho escravo contemporâneo: o exemplo do Brasil. Brasília: Organização Internacional do Trabalho, 2010. Disponível em: <https://goo.gl/q21rp5>. Acesso em: 14 jul. 2016.

ESTERCI, N.; FIGUEIRA, R. R. Trabalho Escravo no Brasil: as lutas pelo reconhecimento como crime de condutas patronais escravistas. In: Revista da Faculdade de Serviço Social da Universidade do Estado do Rio de Janeiro, n. 20, p. 85-97, 2007.

ORGANIZAÇÃO DAS NAÇÕES UNIDAS. Nações Unidas no Brasil. Trabalho escravo. Brasília: Organização das Nações Unidas, 2016. Disponível em: <https://goo.gl/KX7wZj>. Acesso em: 5 jul. 2016.

ORGANIZAÇÃO DAS NAÇÕES UNIDAS. R v Wei Tang 200923 VR 332. Case Law Database. Nova Iorque, 9 nov. 2009. Disponível em: <https:/goo.gl/myMQAl>. Acesso em: 29 nov. 2016.

ORGANIZAÇÃO DAS NAÇÕES UNIDAS. Tribunal Penal Internacional para a Antiga Iugoslávia. Prosecutor v. Dragoljub Kunarac et al. Haia, 12 de junho de 2002. Disponível em: $<$ https://goo.gl/SjG5ml>. Acesso em: 14 jul. 2016.

ORGANIZAÇÃO INTERNACIONAL DO TRABALHO. CONFERÊNCIA INTERNACIONAL DO TRABALHO. Actas Provisionales - 103. ${ }^{a}$ reunión, Ginebra, mayo-junio de 2014. Genebra, Suíça: Organização Internacional do Trabalho, 2014. Disponível em: <https://goo.gl/PHQWki>. Acesso em: 5 jul. 2016.

REINO UNIDO. The UK Parliament. Modern Slavery Act 2015 Explanatory Notes. Londres, 26 de março de 2015 (2015b). Disponível em: <https://goo.gl/WG29pB>. Acesso em: 14 jul. 2016.

REINO UNIDO. The UK Parliament. Modern Slavery Act 2015. Londres, 26 de março de 2015 (2015a). Disponível em: <https://goo.gl/r4VQCg>. Acesso em: 14 jul. 2016. 
SAKAMOTO, Leonardo. "Lista de transparência” traz 349 nomes flagrados por trabalho escravo. Repórter Brasil, São Paulo, 6 jun. 2016. Disponível em: <https://goo.gl/0N8fnf>. Acesso em: 25 jul. 2016.

TRABALHO escravo: pela primeira vez, maior número de resgatados vem de áreas urbanas. Rede Brasil Atual, São Paulo, 14 mai. 2014. Disponível em: <https://goo.gl/wfWx5t>. Acesso em: 14 jul. 2016.

VIANA, Márcio Túlio. Trabalho escravo e "lista suja”: um modo original de se remover uma mancha. In: Revista do Tribunal Regional do Trabalho da $3^{\text {a }}$ região, Belo Horizonte, v. 44, n. 74, p. 189215, jul./dez.2006. Disponível em: <https://goo.gl/mDg7bG>. Acesso em: 5 jul. 2016.

Silvio Beltramelli Neto

Doutor em Direito do Trabalho pela Universidade de São Paulo (Largo São Francisco). Mestre em Direito pela Universidade Metodista de Piracicaba (Unimep). Especialista em Direito e Processo do Trabalho pela Pontifícia Universidade Católica de Campinas (PUCCampinas). Professor na Faculdade de Direito da PUC-Campinas. Procurador do Trabalho (Campinas, SP, Brasil).E-mail: silviobeltramelli@gmail.com

Felipe da Silva Pinto Adão

Bacharel Ciências Jurídicas e Sociais pela Faculdade de Direito da Pontifícia Universidade Católica de Campinas. Assessor Jurídico no Ministério Público do Trabalho (Campinas, SP, Brasil).E-mail: felipe.adao@hotmail.com 